University of Texas Rio Grande Valley

ScholarWorks @ UTRGV

$12-2016$

\title{
Latent Classes of Childhood Poly-victimization and Associations with Suicidal Behavior among Adult Trauma Victims: Moderating Role of Anger
}

\author{
Ruby Charak \\ The University of Texas Rio Grande Valley, ruby.charak@utrgv.edu \\ Brianna M. Byllesby \\ Summa Health Traumatic Stress Center \\ Michelle E. Roley \\ The Ohio State University \\ Meredith A. Claycomb \\ The University of Toledo \\ Tory A. Durham \\ The University of Toledo \\ See next page for additional authors \\ Follow this and additional works at: https://scholarworks.utrgv.edu/psy_fac \\ Part of the Child Psychology Commons
}

\section{Recommended Citation}

Charak, R., Byllesby, B. M., Roley, M., Claycomb, M. A., Durham, T. A., Ross, J., Armour, C., \& Elhai, J. D. (2016). Latent classes of childhood poly-victimization and association with suicidal behavior among adult trauma victims: Moderating role of anger. Child Abuse and Neglect, 62, 19-28. doi.org/10.1016/ j.chiabu.2016.10.010

This Article is brought to you for free and open access by the College of Liberal Arts at ScholarWorks @ UTRGV. It has been accepted for inclusion in Psychological Science Faculty Publications and Presentations by an authorized administrator of ScholarWorks @ UTRGV. For more information, please contact justin.white@utrgv.edu, william.flores01@utrgv.edu. 


\section{Authors}

Ruby Charak, Brianna M. Byllesby, Michelle E. Roley, Meredith A. Claycomb, Tory A. Durham, Jana Ross, Cherie Armour, and Jon D. Elhai 
APA Citation.

Charak, R., Byllesby, B. M., Roley, M., Claycomb, M. A., Durham, T. A., Ross, J., Armour, C., \& Elhai, J. D. (2016). Latent classes of childhood poly-victimization and association with suicidal behavior among adult trauma victims: Moderating role of anger. Child Abuse and Neglect, 62, 19-28. doi.org/10.1016/j.chiabu.2016.10.010

Note. The following document is the final version of the accepted manuscript (Post peerreview; before the proof-reading stage). It may differ from the published article. 


\section{*2. Title page with author details/author acknowledgements}

Childhood victimization, anger, and suicidal behavior

Latent Classes of Childhood Poly-victimization and Associations with Suicidal Behavior among Adult Trauma Victims: Moderating Role of Anger

Ruby Charak

Department of Psychological Science, The University of Texas Rio Grande Valley, Texas Brianna M. Byllesby

Department of Psychology, University of Toledo, Ohio

Michelle E. Roley

Department of Psychiatry, The Ohio State University Wexner Medical Center, Ohio

Meredith A. Claycomb

Tory A. Durham

Department of Psychology, University of Toledo, Ohio

Jana Ross

Cherie Armour

Psychology Research Institute, Ulster University, Northern Ireland

Jon D. Elhai

Department of Psychology; and Department of Psychiatry, University of Toledo, Ohio

Corresponding author: Ruby Charak, Ph.D., Assistant Professor, Department of

Psychological Science, ELABN 361, The University of Texas Rio Grande Valley, Edinburg, Texas. Ph: +1(956) 6653733. Email: ruby.charak@utrgv.edu 


\begin{abstract}
The aims of the present study were first to identify discrete patterns of childhood victimization experiences including crime, child maltreatment, peer/sibling victimization, sexual violence, and witnessing violence among adult trauma victims using latent class analysis; second, to examine the association between class-membership and suicidal behavior, and third to investigate the differential role of dispositional anger on the association between class-membership and suicidal behavior. We hypothesized that those classes with accumulating exposure to different types of childhood victimization (e.g., poly-victimization) would endorse higher suicidal behavior, than the other less severe classes, and those in the most severe class with higher anger trait would have stronger association with suicidal behavior. Respondents were 346 adults $\left(N=346 ; M_{\text {age }}=35.0\right.$ years; $55.9 \%$ female $)$ who had experienced a lifetime traumatic event. Sixty four percent had experienced poly-victimization (four or more victimization experiences) and $38.8 \%$ met the cut-off score for suicidal behavior. Three distinct classes emerged namely, the Least victimization (Class 1), the Predominantly crime and sibling/peer victimization (Class 2), and the Poly-victimization (Class 3) classes. Regression analysis controlling for age and gender indicated that only the main effect of anger was significantly associated with suicidal behavior. The interaction term suggested that those in the Poly-victimization class were higher on suicidal behavior as a result of a stronger association between anger and suicidal behavior in contrast to the association found in Class 2. Clinical implications of findings entail imparting anger management skills to facilitate wellbeing among adult with childhood poly-victimization experiences.
\end{abstract}

Keywords: Poly-victimization, Childhood victimization, Anger, Suicidal behavior, Latent class analysis, Adult trauma victims 


\section{Latent Classes of Childhood Poly-victimization and Associations with Suicidal Behavior among Adult Trauma Victims: Moderating Role of Anger}

Adverse experiences during childhood, including abuse and neglect, victimization by peers/siblings, assault, and witnessing violence, have implications for adolescent (Charak \& Koot, 2015; Elklit, Karstoft, Armour, Feddern, \& Christoffersen, 2013; Ford, Elhai, Connor, \& Frueh, 2010) and adult psychopathology (e.g., emotional distress, mood disorders, substance use, and suicide risk; Benjet, Borges, \& Medina-Mora, 2010; Fergusson, McLeod, \& Horwood, 2013; Hoertel et al., 2015; Spinhoven et al., 2010). Most studies, however, focus on specific types of victimization (e.g., sexual abuse) or combine exposure to any type of victimization into a single group (e.g., victimized versus non-victimized), regardless of the types of victimization experienced. In contrast, studies indicate that different types of victimization during childhood often co-occur, a phenomenon referred to as 'multi-type victimization' (Higgins \& McCabe, 2001) or 'poly-victimization' (Finkelhor, Ormrod, \& Turner, 2007). The former takes into account the presence of different types of child maltreatment experiences, while poly-victimization refers to an array of potentially traumatic events, namely, exposure to conventional crime, child maltreatment, victimization by peer/sibling, sexual violence and witnessing violence (e.g., domestic violence, war; Finkelhor et al., 2007). Hence, poly-victims experience maltreatment in several contexts, including within and outside the family context. In the current study, we investigated patterns of exposure to different types of childhood victimization in adults with experiences of lifetime trauma, and examined the effect of exposure to poly-victimization (versus other types of victimization) on suicidal behavior.

\section{Childhood Poly-victimization}

Prior research work indicates that poly-victimization is prevalent among children and adolescents. In a nationally representative sample aged 2-17 years from the United States, it 
was found that $22 \%$ of the children experience four or more different kinds of victimization, or poly-victimization, in a single year (Finkelhor et al., 2007). In line with this, by employing newer analytic techniques, such as latent class analysis, studies have started to identify discrete groups or classes based on different types of childhood victimization experiences. For example, Grasso et al. (2013) examined distinct patterns of victimization based on exposure to sexual abuse, physical abuse, and witnessing intimate partner violence (IPV) among children and adolescents in Navy families. They found three classes that best represented the sample, and included a class high on all three types of victimization (Class 1), those high on physical abuse and witnessing IPV (Class 2), and a class high on physical abuse (Class 3). In another study on adolescents from Greenland, three victimization classes were found among adolescents: the violence, neglect, and bullying class (Class 1), a class with multiple potentially traumatic events (Class 2), and class with no or limited victimization histories (Class 3; Karsberg, Armour, \& Elklit, 2014).

Studies on poly-victimized children/adolescents further suggest that victims report greater psychological problems, including distress, posttraumatic stress symptoms, depression, suicidal behavior, and substance use problems (e.g., Finkelhor et al., 2007; Ford et al., 2010; Ford, Grasso, Hawke, \& Chapman, 2013; Grasso et al., 2013; Karsberg, Armour, \& Elklit, 2014). Few studies have assessed the effects of childhood poly-victimization on psychopathology in an adult sample (e.g., Radatz \& Wright, 2015; Richmond, Elliott, Pierce, Aspelmeier, \& Alexander, 2009), and studies that do suggest greater psychological problems among adults as well. For example, Hooven, Nurius, Logan-Greene, and Thompson (2012) used a longitudinal design to show that young adults with a history of poly-victimization during adolescence were more likely to experience emotional distress and were higher on suicide risk behavior. Thus, emerging evidence suggests the presence of varying patterns of 
childhood victimization, and investigating differences in psychological outcomes across these patterns of victimization is warranted for tailoring preventative and clinical interventions.

\section{Childhood Poly-victimization and Lifetime Suicidal Behavior Among Adults:}

\section{Cumulative Risk Theory}

An important distal risk factor often related to suicide behavior is exposure to various childhood adversities, including childhood victimization (Ystgaard, Hestetun, Loeb, \& Mehlum, 2004; Soler, Segura, Kirchner, \& Forns, 2013). In a study based on the National Comorbidity Survey (NCS), Joiner et al. (2007) found that adults with childhood physical and/or sexual abuse were more likely to have a higher number of lifetime suicide attempts, when compared to those with childhood verbal abuse or assault experiences. Among adults admitted to a hospital for a suicide attempt, it was found that after controlling for other types of childhood adversities, childhood physical and sexual abuse were predictive of chronic suicidal behavior (Ystgaard et al., 2004). In contrast, more recent studies support an association between childhood emotional maltreatment and neglect, and risk of suicide attempts after controlling for other types of abuse and neglect among adult (de Araujo \& Lara, 2016; Springe et al., 2016). Taken together, prior research demonstrates an association between exposure to various types of childhood victimization and lifetime suicide risk among adults.

The additive effects of exposure to various types of victimization experiences on stress, and short-and long-term psychopathology are well established (Charak, Koot, Dvorak, Elklit, \& Elhai, 2015; Chartier, Walker, \& Naimark, 2010; Rutter, 1988). Such effects are based on the cumulative risk theory which states that the higher the number of risk factors a person is exposed to, the higher the potential for a negative outcome (Appleyward, Egeland, van Dulmen, \& Sroufe, 2005; Rutter, 1979). These dose-response effects of cumulative exposure of childhood victimization have also been found on suicidal behavior in adolescents 
(Chan, 2013; Ford et al., 2013; Fergusson \& Lynskey, 1995) and adults (Belik et al., 2007;

Belik et al., 2009; Stein et al., 2010). However, some victims of childhood maltreatment may be more at risk of suicidal behavior than others. A large range of familial and community level factors (e.g., substance use by parents, access to guns) and individual factors (e.g., shame proneness, personality traits) play important roles in identifying individuals who go on have suicidal behavior (cf. Sareen et al., 2014). The identification of such impelling factors in addition to experiences of childhood victimization facilitates understanding of the role of risk factors leading up to suicidal behavior, and in turn would aid the formulation of clinical interventions.

\section{Childhood Victimization and Suicidal Behavior: The Role of Dispositional Anger}

One risk factor that may work in conjunction to childhood victimization and lead to suicidal behavior is trait anger and anger expressed outwardly (Daniel, Goldston, Erkanli, Franklin, \& Mayfield, 2009). Anger can have adaptive functions such as mobilizing resources to deal with a perceived threat; however anger may also become exaggerated and dysfunctional (Tafrate, Kassinove, \& Dundin, 2002). Trait anger which is the tendency to experience anger in a variety of situations (Spielberger, 1999) may function as a risk factor because of its potential to heighten a person's readiness to respond aggressively and impulsively. Investigators have theorized that emotion dysregulation is the underlying mechanism linking anger with suicide attempts, such that dysregulation of anger leads to suicidality through an individual's reduced ability to cope and control negative affect (Ammerman, Kleiman, Uyeji, Knorr, \& McCloskey, 2015; Giegling et al., 2009). Further, Sadeh and McNeil (2013) found that facets of anger disposition related to physiological arousal, hostile cognitions, and angry behavior, predicted suicide attempts among survivors of childhood sexual abuse. 
In addition, studies support that those with poly-victimization experiences are higher on anger than other individuals with lesser adverse childhood experiences (Turner et al., 2006). For example, in a juvenile justice-involved youth sample, Ford et al. (2013) examined different types of traumatic events and adversities that represented seven domains of victimization (e.g., physical assault, neglect) and two domains of non-victimization adversity (e.g., loss of loved one, illness), and found three groups differing in victimization experiences. Specifically, there was a low adversity class, moderate adversity class and a poly-victim class, with corresponding increase in problems of alcohol/drug use, anger/irritability, and suicide ideation across the three classes, respectively. Taken together, the interplay between poly-victimization, dispositional anger, and suicidal behavior raises the possibility that higher anger-trait potentiates the risk of suicidal behavior associated with poly-victimization. In the present study, we assess dispositional anger (or trait anger) and propose that those with multiple victimization and higher on anger trait would be higher on suicidal behavior, that is, anger trait would moderate the association between childhood victimization and suicidal behavior. By examining the interactions between classmembership based on types of childhood adversities, and trait anger the present study aims to understand how childhood adversity and anger in combination may lead to an increase in prediction of suicidal behavior and yield findings that inform suicide risk assessments.

\section{The Current Study}

In sum, there are varying patterns of childhood victimization, and studies indicate a cumulative effect of multiple victimization experiences during childhood on adult suicide risk behavior. The present study aims to examine the presence of discrete classes of childhood victimization experiences among adults with lifetime trauma exposure. We investigated anger as a moderator of the association among these latent classes and suicide behavior. Specifically, we first hypothesized that there would be mutually exclusive classes of adults 
with varying experiences of childhood victimization with at least one class endorsing multiple types of childhood victimization or poly-victimization (Finkelhor et al., 2007; Ford et al., 2010). Second, based on the cumulative risk theory, we hypothesized that classes with adults endorsing poly-victimization would be higher on suicidal behavior than classes with fewer victimization experiences (Belik et al., 2009; Stein et al., 2010). Third, we hypothesized that anger would moderate the association between class-membership and suicidal behavior, such that the slope indicating the relation between anger and suicidal behavior will be significantly different (i.e., steeper) for those in the class endorsing polyvictimization than those classes with less severe victimization. In other words, those in the poly-victimization class will have a stronger association (i.e., steeper slope) between anger and suicidal behavior compared to the association found in the other less severe classes.

\section{Method}

\section{Participants \& Procedure}

The present study is based on data collected primarily to understand traumatic stress among those with a history of lifetime trauma. The initial round of data collection started with 801 respondents participating through Amazon's Mechanical Turk (MTurk) in Spring 2015. MTurk platform has been found acceptable for participant recruitment with studies supporting that it often more representative of the general population than other convenience samples (Berinsky, Huber, \& Lenz, 2012). We excluded individuals who did not endorse a history of psychological trauma $(N=198)$. Of the remaining 603 individuals, 133 respondents were excluded as they were from outside the U.S. or Canada, or were disqualified based on no trauma and attempted reentry into the survey $(N=30)$, or did not answer any of the survey items except reporting their nationality $(N=37)$, or incorrect screening items gauging attention $(N=37)$. This left the sample of 366 respondents who were administered the full survey and each was paid 50 cents for participation. Among these, 20 
were excluded as no information regarding their age, gender, and all childhood victimization subtypes (see measures section for scale details) was available. The present study comprised an effective sample of 346 respondents in the age range of 18-74 years $(M=35.0, S D=$ $11.84 ; 55.9 \%$ female) who had endorsed at least one lifetime trauma event.

Nearly a quarter of the respondents reported their worst trauma as death of someone close, $15 \%$ reported a life-threatening illness, $9.2 \%$ sexual assault by force, $7.5 \%$ physical harm by caregiver, $7.2 \%$ life threatening accident, $6.6 \%$ inappropriate fondling during childhood, $6.4 \%$ partner/date violence, $5.2 \%$ physical assault in the presence of weapon, $4.9 \%$ repeated exposure to vivid trauma details, $4 \%$ being threatened with a weapon, $3.8 \%$ sexual assault by threat, $2.9 \%$ serious injury, and $2.3 \%$ witnessed murder, injury or assault. Based on the last time/age when the respondents experienced the worst traumatic event, $30.3 \%$ had experienced it during childhood and the remaining endorsed experiencing their worst trauma during adulthood. Respondents self-reported racial background (not mutually exclusive) comprised 70.2\% White, 13.9\% Asian, 11.6\% Black, 8.4\% American Indian or Alaskan Native, $0.9 \%$ Native Hawaiian/other Pacific Islanders, and 2.3\% did not report their race. Nearly $15 \%$ endorsed their ethnicity as Hispanic. The present study was approved by the Institutional Review Board (IRB) of a mid-western University in the United States where the study was formulated and conducted.

\section{Measures}

Childhood victimization. To assess childhood victimization experiences the Juvenile Victimization Questionnaire-second revision (JVQ-R2; Finkelhor, Hamby, Turner, \& Ormrod, 2011) adult retrospective form was used. The JVQ-R2 assesses childhood victimization from birth to age of 17 . It has 34 screener items assessing conventional crime comprising items that parallel the offenses defined and measured by the U.S. Federal Government in the National Crime Victimization Survey (9 items; Rennison \& Rand, 2003), 
childhood maltreatment by caregivers (4 items), peer and/or sibling victimization (6 items), sexual victimization within and outside the family (7 items), and witnessing and other exposure to violence (8 items). The response options were Yes/No (i.e., 1 or 0 , respectively). For the present study, endorsing any item in a subscale was considered as presence of that particular childhood victimization. The Cronbach's alpha for the JVQ scales ranged from .66.79 in the present study.

Anger. The Dimensions of Anger Reactions (DAR; Novaco, 1975; Novaco, Swanson, Gonzalez, Gahm, \& Reger, 2012) is a 7-item questionnaire measuring anger disposition. Four items pertain to response parameters assessing anger frequency, intensity, duration, and physical antagonism, and three items concern anger's perceived negative impact on social relationships, work, and health. The response options range from not at all to exactly so $(0-8$; range 0-56) to indicate the degree to which each statement describes respondents' feelings and behavior. A higher score indicates greater anger disposition. A factor analytic examination of the DAR suggests a one-factor solution (Forbes et al., 2004). The scale has demonstrated good internal consistency, with item-total correlations ranging from .72 to .89 (Forbes et al., 2004; Novaco et al., 2012). Validity for the DAR is good, with moderate correlations between the DAR and the State anger $(r=.41)$ and high correlation between the DAR and Trait anger $(r=.79)$ subscales of the State-Trait Anger Expressions Inventory (Forbes et al., 2004). In the present study, the Cronbach alpha for the DAR scale was .93.

Suicidal behavior. The Suicidal Behaviors Questionnaire-Revised (SBQ-R; Osman et al., 2001) comprises four items, each tapping a different dimension of suicidal behavior. Item 1 assesses lifetime suicide ideation and suicide attempts, item 2 assesses the frequency of suicidal ideation over the past year, item 3 taps into suicide intent, and item 4 evaluates self-reported likelihood of a future attempt. The range of scores is from 3-18. A cut-off score of 7 or above in an adult general population had a sensitivity of $93 \%$ and specificity of $95 \%$ 
(Osman et al., 2001). In other words, individuals who score 7 or above are at risk of having suicide-related behavior, such as suicide ideation, attempt, or intent and future suicideattempt. The SBQ-R has shown good internal consistency $(\alpha=.76-.88)$ and adequate to excellent construct, concurrent, and divergent validity (Osman et al., 2001). The Cronbach alpha in the present study was .82 .

\section{Statistical Analyses}

First, we assessed the distribution of respondents and gender distribution across the five different types of childhood victimization, and assessed the partial correlations between each type of childhood victimization and suicidal behavior controlling for age, gender, and the other four types of childhood victimization. Second, a latent class analysis (LCA) was carried out to determine the number of heterogeneous groups based on types of victimization experiences. LCA estimates the posterior probabilities of class membership or size of the class (Nylund et al., 2007). Better fitting models are reflected by non-significant $p$ values for the Lo-Mendell-Rubin's likelihood ratio test (LMR; Lo, Mendell, \& Rubin, 2001) when compared to model with one fewer class, low values on the Akaike Information Criteria (AIC; Akaike, 1987), the Bayesian Information Criteria (BIC; Schwarz, 1978), and the sample size adjusted BIC (Adjusted BIC; Sclove, 1987). Higher entropy values indicate clearer classification (Ramaswamy, DeSarbo, Reibstein, \& Robinson, 1993). Furthermore, model fit and the resultant class solution should be judged based on substantive meaningfulness of the classes, i.e., the classes should be distinct and meaningful (Nylund et al., 2007). The LCA analysis was conducted using Mplus 6.11 software employing maximum likelihood estimation with robust standard errors (MLR). After obtaining the victimization classes, we exported them into IBM SPSS version 20.0 for further analysis. Third, we created dummy-coded variables for class-membership and tested the effect of class-membership, and 
anger on suicidal behavior. Fourth, we assessed the differential role of anger in the association between class-membership and suicidal behavior.

\section{Results}

Missing data on the study variables ranged from $.3-5.2 \%\left(N_{\text {range }}=1-18\right)$. Since percentage of missing values was low we used full information maximum likelihood (FIML) while conducting LCA.

\section{Distribution and Partial Correlation of Different Types of Childhood Victimization}

Table 1 shows the percentage of respondents endorsing each item of the JVQ-R2, along with percentage endorsement of exposure to conventional crime, child maltreatment, peer/sibling abuse, sexual violence, and witnessing indirect violence. Nearly $94 \%$ of the respondents reported one or more types of childhood victimization experiences. Among these, $10.8 \%$ of the respondents had experienced two types of victimization, $12.5 \%$ reported three types of childhood victimization, $24.4 \%$ had experienced four different types of victimization, and $39.5 \%$ reported all five types of childhood victimization experiences. As per the cut-off for poly-victimization - that is, experiencing four or more victimization experiences - nearly $64 \%$ of the respondents reported having experienced poly-victimization (Finkelhor et al., 2007). Suicidal behavior (cutoff $\geq 7$ on SBQ-R) was found in $38.8 \%$ of the respondents, that is, these individuals were at risk of having suicide-related behavior, such as suicide ideation, attempt, or intent and future suicide-attempt. Further, partial correlation between presence of childhood maltreatment and suicidal behavior $(r=.20, p<.001)$ was the only significant correlation controlling for age, gender, and exposure to other four types of childhood victimization. No other subtype of childhood victimization was uniquely associated with suicidal behavior (range of $r=.03-.09, p>.05$ ).

\section{Latent Classes of Childhood Victimization Experiences}


A series of LCA models with a 2-6 class solutions were estimated. A three-class solution was found to be the optimal solution based on a number of fit indices (see Table 2), and conceptual validity. The LMR test favored the three-class solution in contrast to a 2 or 4 class solution. The Bayesian information criteria clearly favored the three-class solution in comparison to Class 4 . The entropy was moderate and the average posterior probability for most likely latent class membership ranged from $.83-.90$ for the three-class solution, which is suggestive of good class determination. A 5-class solution did not lead to any further improvement in fit indices, and 6-class solution did not converge suggestive of excessive extraction of classes.

The three latent classes were labeled according to the type of childhood victimization endorsed (Figure 1). Class 1 was labeled Least victimization (13\%) as few respondents in this class endorsed experiencing crime or maltreatment during their childhood and none endorsed peer/sibling victimization, sexual victimization or witnessing any type of indirect violence. Class 2 (22.3\%) was labeled as Predominantly crime and sibling/peer victimization as nearly $75-80 \%$ of the respondents in this class had experienced conventional crime and victimization by a peer or a sibling. The third class was called Poly-victimization $(64.7 \%)$ as nearly all respondents reported being victims of conventional crime, peer/sibling victimization, and had witnessed indirect violence. In addition, 90-96\% in this class endorsed having experienced childhood maltreatment including sexual victimization.

\section{Effect of Class-membership on Suicide Behavior: Moderating Role of Anger}

Analysis of variance indicated that there was a significant association between classmembership and suicidal behavior $\left(F[2,342]=21.48, p<.001, \eta^{2}=.11\right)$. Further, post-hoc analysis indicated that Poly-victimization class (Class $3 ;$ Mean $_{3}=7.4$ ) was significantly higher than Least victimization class (Class $1 ;$ Mean $\left._{1}=4.44\right)$, and Predominantly sibling/peer victimization class (Class 2; $\left.\mathrm{Mean}_{2}=5.1\right)$ on suicidal behavior. Additionally, out of the 134 
respondents who had a cut-off score $\geq 7,110$ (82.1\%), were in the Poly-victimization Class followed by Class $2(N=16)$, and the remaining eight respondents were in Class 1 . The developmental stage (childhood vs. adulthood) at which the worst trauma was experienced was not significantly associated with suicidal behavior $(F[1,343]=.99, p=.32)$ suggestive of no difference on suicidal behavior among respondents who endorsed experiencing worst trauma in childhood versus those who endorsed experiencing it during adulthood. Further, the correlation between anger and suicidal behavior was moderate $(r=.40, p<.001)$.

Next, we built two separate models, each involving a 3-step hierarchical regression analyses to assess the effects of class-membership (dummy-coded; with Class 3 as the reference class), anger, and their interaction-term (i.e., class-membership x anger) on suicidal behavior. The analysis controlled for the effects of age and gender which were entered in step-1, followed by the main effects of class-membership and anger in step-2 and in step-3 the interaction-term between class-membership and anger was entered (Table 3). Results in step 1 from models 1-2, indicated that age had a significant negative effect on suicidal behavior, that is, being younger in age was associated with higher suicidal behavior $(B=-.04$, $p<.05)$. No significant association was found between gender and suicidal behavior $(B=-$ $.53, p=.19)$. Results from step 2 of model 1 indicated that compared to the respondents in the Poly-victimization class, those in the Least victimization class were significantly lower on suicidal behavior $(B=-1.71, p<.01)$, and those scoring higher on anger reactivity were higher on suicidal behavior $(B=.09, p<.001)$. However, anger did not have a differential effect on the association between class-membership and suicidal behavior in model 1. In particular, the slope or the association between anger and suicidal behavior did not differ significantly as a result of being in the Poly-victimization class $(\beta=.37, p<.001)$ or the Least Victimization $(\beta=.38, p<.01)$ class. In model-2 step- 2 , analysis indicated that compared to the respondents in the Poly-victimization class, those in the Predominantly 
crime and sibling/peer victimization class were significantly lower on suicidal behavior $(B=-$ $1.29, p<.01$ ), and those scoring higher on anger reactivity were higher on suicidal behavior $(B=.09, p<.001)$. Further results from step-3 indicated that anger moderated the association between class-membership (i.e., Predominantly sibling/peer victimization class versus Polyvictimization class $)$ and suicidal behavior $(B=-0.07, p=.045)$. Specifically, the slope of anger and suicidal behavior in the Poly-victimization class was significantly steeper $(\beta=.41$, $p<.001)$ than the slope in the Predominantly sibling/peer victimization class $(\beta=.16, p=$ .20) as shown in Figure 2.

\section{Discussion}

The present study investigated the presence of mutually exclusive classes based on exposure to five different types of childhood victimization, namely, exposure to conventional crime, childhood maltreatment (physical abuse, neglect, or emotional abuse), peer and/or sibling victimization, sexual victimization, and witnessing and other exposure to violence in adult victims of trauma. Supporting our first hypothesis, three latent classes emerged and parallel past research with community and clinical samples (Alvarez-Lister et al., 2014; Ford et al., 2010; 2013) highlighting the presence of poly-victimization, victimization among contemporaries, that is among siblings or peers, and those with least victimization. As discussed below, our second hypothesis that adults with exposure to different types of childhood victimization (i.e., Poly-victimization class) would report higher suicidal behavior than those in the lesser severe classes (Classes 1 and 2) was supported, but only when the effect of anger was not taken into account. And finally, the third hypothesis was partially supported as anger had a differential effect on the association between class-membership and suicidal behavior, such that it moderated the association between Predominantly sibling/peer victimization class versus Poly-victimization class, and suicidal behavior. Specifically, the association between anger and suicidal behavior was higher among those in the Poly- 
victimization class than those in the Predominantly sibling/peer victimization class. The findings, implications and suggestions for further research are suggested below.

Among trauma-exposed adults, we found three-classes with varying exposure to childhood victimization. These latent classes were labeled as Least victimization (Class 1), Predominantly crime and sibling/peer victimization (Class 2), and Poly-victimization (Class 3). A number of prior studies support the presence of discrete classes based on differential exposure to childhood victimization (Ford et al., 2010, 2013). Notably, the number of classes found in previous studies on adolescents range from 3-6 classes among those from the community (e.g., 3-classes among students from schools in Greenland; Karsberg et al., 2014), in the juvenile detention centers (3-classes; Ford et al., 2013), and a U.S. nationally representative sample (6-classess; Ford et al., 2010). The class distribution in these studies represents a class with experiences of least number of adversities or a normative class (e.g., Class 2; Ford et al., 2013; Class 3; Karsberg et al., 2014), moderate adversity involving motor vehicle accidents, physical assault, neglect, and bullying (Class 1; Ford et al., 2013; Class 2; Karsberg et al., 2014), and a class with multiple experiences of victimization or polyvictimization (Classes 1, 2, 4, and 6; Ford et al., 2010; Class 3; Ford et al., 2013; Class 1; Karsberg et al., 2014). Our finding of three discrete latent classes of childhood victimization among adult-trauma victims bear semblance to the latent classes found in prior studies as we found a class with least victimization endorsing crime and maltreatment only, a class with moderate level of victimization (Class 2), and class with most respondents endorsing experiences of all types of victimization (Class 3). The present study findings add to the growing body of research supporting the co-occurrence of different childhood victimization experiences and varying patterns of exposure (Finkelhor et al., 2007).

Supporting our second hypothesis, findings suggest that those with the Least victimization experiences (Class 1) and those with Predominantly crime and sibling/peer 
victimization (Class 2) were less likely to endorse suicidal behavior as compared to those with experiences of Poly-victimization (Class 3) who in turn were at a higher risk of suicidal behavior. Notably, $82.1 \%$ of respondents who met the criteria of suicidal behavior were in the Poly-victimization Class. However, these findings were found at a univariate level and before controlling for the effect of anger. Nonetheless, these findings are consistent with prior research, in that they illustrate the accumulating and detrimental impact of different types of childhood victimization experiences on risk of suicidal behavior among adolescents and young adults (Ramiro, Madrid, \& Brown, 2010; Tossone et al., 2015). Although not a part of our hypothesis, an examination of the unique association between each type of childhood victimization exposure with suicidal behavior, after controlling for age, gender, and the other types of childhood victimization, suggests that only childhood maltreatment experiences were significantly correlated with suicidal behavior after controlling for age, gender, and effect of other childhood victimization. Findings highlight that in contrast to other types of childhood victimization experiences, including sexual abuse, the presence of any childhood maltreatment—physical abuse, neglect, or emotional abuse—was most strongly associated with suicidal behavior. Notably, child maltreatment experiences in the present study were specific to perpetration by a caregiver, whereas sexual victimization or assault included intrafamilial and extra-familial perpetration. It may be that those with intra-familial child maltreatment were more likely to have experienced chronic and higher frequency of maltreatment: abuse-characteristics that lead to increase in severity of maltreatment (English et al., 2005). These finding supports the association between interpersonal traumatic events, such as child maltreatment within the family context on lifetime suicide risk among adults (Rajalin et al., 2013). However findings warrant future investigation of multiple types of victimization while also considering the severity levels of these experiences. 
Our third hypothesis was partially supported, as the differential effect of anger on the association between class-membership and suicidal behavior was found only between the Predominantly crime and sibling/peer victimization class (Class 2) versus the Polyvictimization class (Class 3). Specifically, inclusion of an interaction term between classmembership and anger clearly indicated that the Poly-victimization class (Class 3) had adults with higher anger scores predictive of suicidal behavior (see model 2 in Table 3; Fig 2) than those in the Predominantly crime and sibling/peer victimization class. Prior research with children and adolescents has shown higher scores on anger in those with poly-victimization (e.g., Ford et al., 2013), and studies examining suicide attempts have demonstrated that anger predicts suicide attempts (Ammerman et al., 2015). We posit that this mechanism of coping via anger reactivity may be more ingrained in individuals with childhood poly-victimization, leading to prediction of suicidal behavior, in contrast to those with other victimization experienced in lesser number of contexts (Classes 1 and 2).

The present study is not without limitations. First, self-report measures were used to gather information on childhood victimization which can lead to a recall bias. Further studies should include multi-modal assessment and multiple-informant reports of childhood victimization experiences. Semi-structured clinical interviews should supplement the selfreport used here to assess suicidal behavior. Second, the present sample was limited to those who had experienced at least one traumatic event during their lifetime, and hence our sample is limited in this regard. Notably, studies indicate that a large majority of individuals, that is $50-60 \%$, report at least one lifetime traumatic event based on national survey reports (Kessler, Sonnega, Bromet, Hughes, \& Nelson, 1995). More recently, a U.S. national survey reported this figure to be at $89.7 \%$ (Kilpatrick et al., 2013).

Despite these limitations, the present findings demonstrate that varying patterns of childhood victimization exist, and have relative differences in their effect on suicidal 
behavior during adulthood. In the present study, those in the poly-victimization class had a stronger association between anger and suicidal behavior, in contrast to that found in Class 2 . These findings have implications for clinicians to take a holistic approach while inquiring about exposure to various types of childhood victimization experiences rather than limiting inquiry to a predominant type of victimization (e.g., sexual abuse). Such an approach could facilitate understanding of the co-occurrence of different types of childhood victimization, and their cumulative effect on suicidal behavior. Given the potential lethality of suicide behaviors, these findings are especially important for clinicians. Anger can be a potential barrier to treatment and thus promoting anger management skills could facilitate recognition of triggers and also help in alleviating any distress leading up to suicide behavior. 


\section{References}

Akaike, H. (1987). Factor analysis and AIC. Psychometrika, 52, 317-332.

Alvarez-Lister, M. S., Pereda, N., Abad, J., Guilera, G., \& the GReVIA. (2014).

Polyvictimization and its relationship to symptoms of psychopathology in a southern European sample of adolescent outpatients. Child Abuse and Neglect, 38, 747-756.

Ammerman, B. A., Kleiman, E. M., Uyeji, L. L., Knorr, A. C., \& McCloskey, M. S. (2015).

Suicidal and violent behavior: The role of anger, emotion dysregulation, and impulsivity. Personality and Individual Differences, 79, 57-62.

Appleyard, K., Egeland, B., van Dulmen, M., \& Sroufe, A. (2005). When more is not better: the role of cumulative risk in child behavior outcomes. Journal of Child Psychology and Psychiatry, 46, 235-245.

Belik, S., Cox, B. J., Stein, M. B., Asmundson, G. J. G., \& Sareen, J. (2007). Traumatic events and suicidal behavior: Results from a national mental health survey. Journal of Nervous and Mental Disease, 195, 342-349.

Belik, S., Stein, M. B., Asmundson, G. J. G., \& Sareen, J. (2009). Relation between traumatic events and suicide attempts in Canadian military personnel. The Canadian Journal of Psychiatry, 54, 93-104.

Benjet, C., Borges, G., \& Medina-Mora, M. E. (2010). Chronic childhood adversity and onset of psychopathology during three life stages: Childhood, adolescence and adulthood. Journal of Psychiatric Research, 44, 732-740.

Berinsky, A. J., Huber, G. A., \& Lenz, G. S. (2012). Evaluating online labor markets for experimental research: Amazon.com's Mechanical Turk. Political Analysis, 20, 351368. 
Chan, K. L. (2013). Victimization and poly-victimization among school-aged Chinese adolescents: Prevalence and associations with health. Preventive Medicine, 56, 207210.

Charak, R., \& Koot, H. M. (2015). Severity of maltreatment and personality pathology in adolescents of Jammu, India: A latent class approach. Child Abuse and Neglect, 50, $56-66$.

Charak, R., Koot, H. M., Dvorak, R. D., Elklit, A., \& Elhai, J. D. (2015). Unique versus cumulative effects of physical and sexual assault on patterns of adolescent substance use. Psychiatry Research, 30, 763-769.

Chartier, M. J., Walker, J. R., \& Naimark, B. (2010). Separate and cumulative effects of adverse childhood experiences in predicting adult health and health care utilization. Child Abuse and Neglect, 34, 454-464.

Daniel, S. S., Goldston, D. B., Erkanli, A., Franklin, J. C., \& Mayfield, A. M. (2009). Trait anger, anger expression, and suicide attempts among adolescents and young adults: A prospective study. Journal of Clinical Child and Adolescent Psychology, 38, 661-671. de Araujo, R. M. F., \& Lara, D. R. (2016). More than words: The association of childhood emotional abuse and suicidal behavior. European Psychiatry, 37, 14-21.

Elklit, A., Karstoft, K., Armour, C., Feddern, D., \& Christoffersen, M. (2013). Predicting criminality from child maltreatment typologies and posttraumatic stress symptoms. European Journal of Psychotraumatology, 4. doi: 10.3402/ejpt.v410.19825

English, D. J., Upadhyaya, M. P., Litrownik, A. J., Marshall, J. M., Runyan, D. K., Grahan, J. C., \& Dubowitz, H. (2005). Maltreatment's wake: The relationship of maltreatment dimensions to child outcomes. Child Abuse and Neglect, 29, 597-619. 
Fergusson, D. M., \& Lynskey, M. T. (1995). Suicide attempts and suicidal ideation in a birth cohort of 16-year-old New Zealanders. Journal of the American Academy of Child \& Adolescent Psychiatry, 34, 1308-1317.

Fergusson, D. M., McLeod, G. F. H., \& Horwood, J. L. (2013). Childhood sexual abuse and adult developmental outcomes: Findings from a 30-year longitudinal study in New Zealand. Child Abuse and Neglect, 37, 664-674.

Finkelhor, D., Hamby, S., Turner, H., \& Ormrod, R. (2011). The childhood victimization questionnaire: $2^{\text {nd }}$ revision (JVQ-R2). Durham, NH: Crime Against Children Research Center.

Finkelhor, D., Ormrod, R. K., \& Turner, H. A. (2007). Poly-victimization: A neglected component in child victimization. Child Abuse and Neglect, 31, 7-26.

Forbes, D., Hawthorne, G., Elliot, P., McHugh, T., Biddle, D., Creamer, M., \& Novaco, R. W. (2004). A concise measure of anger posttraumatic stress disorder. Journal of Traumatic Stress, 17, 249-256.

Ford, J. D., Elhai, J. D., Connor, D. F., \& Frueh, B. C. (2010). Poly-victimization and risk of posttraumatic, depressive, and substance use disorders and involvement in delinquency in a national sample of adolescents. Journal of Adolescent Health, 46, $545-552$.

Ford, J. D., Grasso, D. J., Hawke, J., \& Chapman, J. F. (2013). Poly-victimization among juvenile justice-involved youths. Child Abuse and Neglect, 37, 788-800.

Giegling, I., Olgiati, P., Hartmann, A. M., Calati, R., Moller, H., Rujescu, D., \& Serretti, A. (2009). Personality and attempted suicide. Analysis of anger, aggression and impulsivity. Journal of Psychiatric Research, 43, 1262-1271. 
Grasso, D., Saunders, B. E., Williams, L. M., Hanson, R., Smith, D. W., \& Fitzgerald, M. M. (2013). Patterns of multiple victimization among maltreated children in navy families. Journal of Traumatic Stress, 26, 597-604.

Higgins, D. J., \& McCabe, M. P. (2001). Multiple forms of child abuse and neglect: Adult retrospective reports. Aggression and Violent Behavior, 6, 547-578.

Hoertel, N., Franco, S., Wall, M. M., Oquendo, M. A., Wang, S., Limosin, F., \& Blanco, C. (2015). Childhood maltreatment and risk of suicide attempt: A nationally representative study. Journal of Clinical Psychiatry, 76, 916-923.

Hooven, C., Nurius, P. S., Logan-Greene, P., \& Thompson, E. A. (2012). Childhood violence exposure: Cumulative and specific effects on adult mental health. Journal of Family Violence, 27, 511-522.

Joiner, T. E., Sachs-Ericsson, N. J., Wingate, L. R., Brown, J. S., Anestis, M. D., \& Selby, E. A. (2007). Childhood physical and sexual abuse and lifetime number of suicide attempts: A persistent and theoretically important relationship. Behaviour Research and Therapy, 45, 539-547.

Karsberg, S., Armour, C., \& Elklit, A. (2014). Patterns of victimization, suicide attempt, and posttraumatic stress disorder in Greenlandic adolescents: A latent class analysis. Social Psychiatry and Psychiatric Epidemiology, 49, 1389-1399.

Kilpatrick, D. G., Resnick, H. S., Milanak, M. E., Miller, M. W., Keyes, K. M., \& Friedman, M. J. (2013). National estimates of exposure to traumatic events and PTSD prevalence using DSM-IV and DSM-5 criteria. Journal of Traumatic Stress, 26, 537-47.

Kessler, R. C., Sonnega, A., Bromet, E., Hughes, M., Nelson, C. B. (1995). Posttraumatic stress disorder in the National Comorbidity Survey. Archives of General Psychiatry, $52,1048-1060$. 
Lo, Y., Mendell, N., \& Rubin, D. (2001). Testing the number of components in a normal mixture. Biometrika, 88, 767-778.

Novaco, R. W. (1975). Dimensions of anger reactions. Irvine, CA: University of California.

Novaco, R., Swanson, R. D., Gonzalez, O. I., Gahm, G. A., \& Reger, M. D. (2012). Anger and postcombat mental health: Validation of a brief anger measure with U.S. soldiers postdeployed from Iraq and Afghanistan. Psychological Assessment, 24, 661-675.

Nylund, K., Asparouhov, T., \& Muthén, B. O. (2007). Deciding on the number of classes in latent class analysis and growth mixture modeling: A Monte Carlo simulation study. Structural Equation Modeling, 14, 535-569.

Osman, A., Bagge, C. L., Guitierrez, P. M., Konick, L. C., Kooper, B. A., \& Barrios, F. X. (2001). The suicidal behaviors questionnaire-revised (SBQ-R): Validation with clinical and nonclinical samples. Assessment, 5, 443-454.

Radatz, D. L., \& Wright, E. M. (2015). Does polyvictimization affect incarcerated and nonincarcerated adult women differently? An exploration into internalizing problems. Journal of Interpersonal Violence. doi: 10.1177/0886260515588921

Rajalin, M., Hirvokoski, T., \& Jokinen, J. (2013). Family history of suicide and exposure to interpersonal violence in childhood predict suicide in male suicide attempters. Journal of Affective Disorders, 148, 92-97.

Ramaswamy, V., DeSarbo, W. S., Reibstein, D. J., \& Robinson, W. T. (1993). An empirical pooling approach for estimating marketing mix elasticities with PIMS data. Marketing Science, 12, 103-124.

Ramiro, L. S., Madrid, B. J., \& Brown, D. W. (2010). Adverse childhood experiences (ACE) and health-risk behaviors among adults in a developing country setting. Child Abuse and Neglect, 34, 842-855. 
Rennison, C. M., \& Rand, M. R. (2003). Criminal victimization, 2002. Washington, DC: US Department of Justice, Office of Justice Programs, Bureau of Justice Statistics.

Richmond, J. M., Elliott, A. N., Pierce, T. W., Aspelmeier, J. E., \& Alexander, A. A. (2009). Polyvictimization, childhood victimization, and psychological distress in college women. Child Maltreatment, 14, 127-147.

Rutter, M. (1979). Protective factors in children's responses to stress and disadvantage. In M. W. Kent, \& J. E. Rolf (Eds.), Primary prevention of psychopathology: Vol. 3. Special competence in children (p. 49-74). Hanover, NH: University Press of New England.

Rutter, M. (1988). Epidemiological approaches to developmental psychopathology. Archives of General Psychiatry, 45, 486-495.

Sadeh, N. \& McNiel, D. E. (2013). Facets of anger, childhood sexual victimization, and gender as predictors of suicide attempts by psychiatric patients after hospital discharge. Journal of Abnormal Psychology, 122, 879-890.

Sareen, J., Isaak, C., Katz, L. Y., Bolton, J., Enns, M. W., \& Stein, M. B. (2014). Promising strategies for advancement in knowledge of suicide risk factors and prevention. American Journal of Preventive Medicine, 47, 257-263.

Schwarz, G. (1978). Estimating the dimension of a model. Annals of Statistics, 6, 461-464.

Sclove, L. (1987). Application of model-selection criteria to some problems in multivariate analysis. Psychometrika, 52, 333-343.

Soler, L., Segura, A., Kirchner, T., \& Forns, M. (2013). Polyvictimization and risk for suicidal phenomena in a community sample of Spanish adolescents. Violence and Victims, 28, 899-912.

Spielberger, C. D. (1999). STAXI-2: State-Trait Anger Expression Inventory-2: Professional manual. Odessa, FL: Psychological Assessment Resources. 
Spinhoven, P., Elzinga, B. M., Hovens, J. G., Roelofs, K., Zitman, F. G., van Oppen, P., \& Pennix, B. W. (2010). The specificity of childhood adversities and negative life events across the life span to anxiety and depressive disorders. Journal of Affective Disorders, 126, 103-12.

Springe, L., Pulmanis, T., Velika, B., Pudule, I., Grinberga, D., \& Villerusa, A. (2016). Selfreported suicide attempts and exposure to different types of violence and neglect during childhood: findings from a young adult population survey in Latvia. Scandinavian Journal of Public Health, 44, 411-417.

Stein, D. J., Chiu, W. T., Hwang, I., Kessler, R. C., Sampson, N., Alonso, J., .. Nock, M. K. (2010). Cross-national analysis of the associations between traumatic events and suicidal behavior: Findings from the WHO World Mental Health Surveys. PLoS ONE, 5, e10574. doi.10.1371/journal.pone.0010574.

Tafrate, R. C., Kassinove, H., \& Dundin, L. (2002). Anger episodes in high-and low-traitanger community adults. Journal of Clinical Psychology, 58, 1573-1590.

Tossone, K., Jefferis, E. S., Grey, S. F., Bilge-Johnson, S., Bhatta, M. P., \& Seifert, P. (2015). Poly-traumatization and harmful behaviors in a sample of emergency department psychiatric intake response center youth. Child Abuse and Neglect, 40, 142-151.

Turner, H. A., Finkelhor, D., \& Ormrod, R. (2006). The effect of lifetime victimization on the mental health of children and adolescents. Social Science \& Medicine, 62, 13-27.

Ystgaard, M., Hestetun, I., Loeb, M., \& Mehlum, L. (2004). Is there a specific relationship between childhood sexual and physical abuse and repeated suicidal behavior. Child Abuse and Neglect, 28, 863-875. 
Childhood victimization, anger, and suicidal behavior

Figure 1

Percentage of respondents endorsing five different types of childhood victimization experiences across the three latent classes

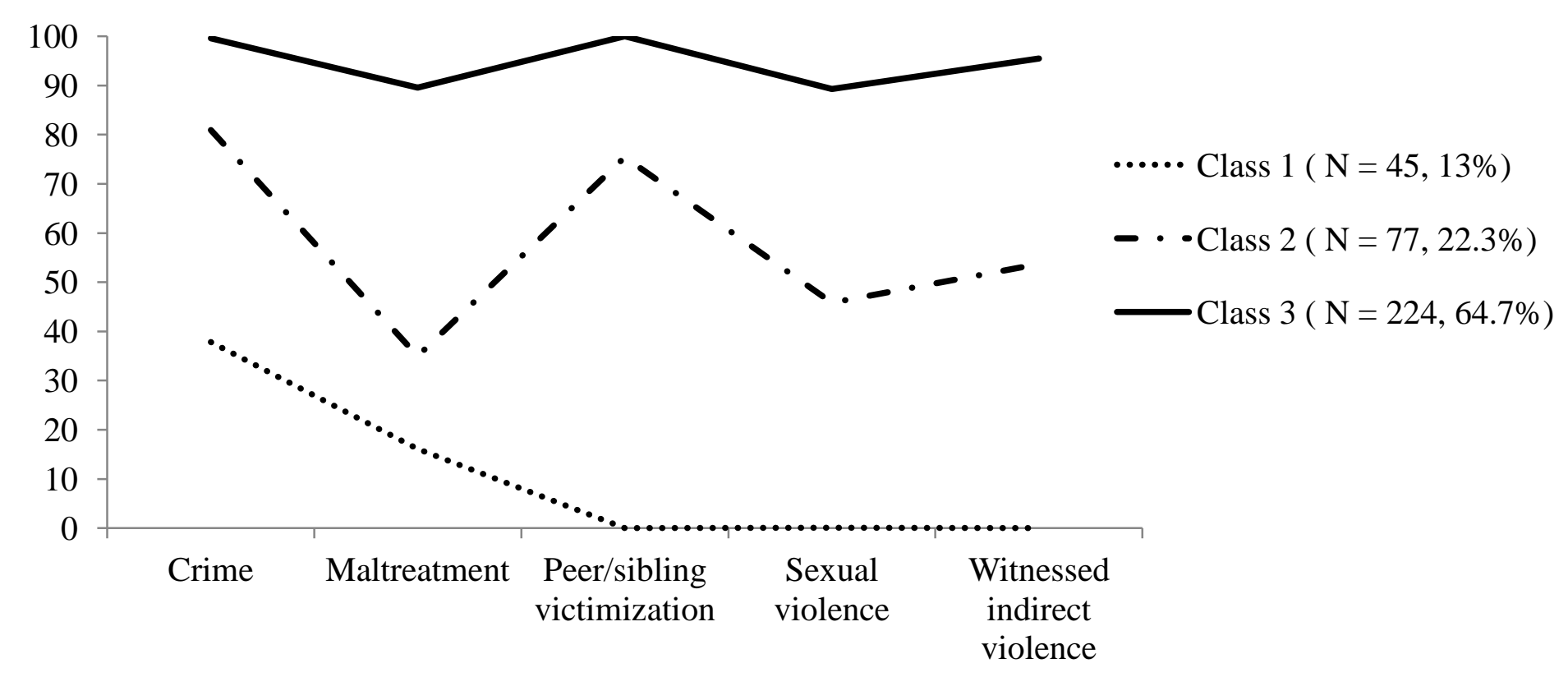

Note: Class 1 = Least victimization; Class 2 = Predominantly crime and sibling/peer victimization; Class $3=$ Poly-victimization. 
Figure 2

Association between anger and suicidal behavior across the Predominantly crime and sibling/peer victimization and Poly-victimization classes

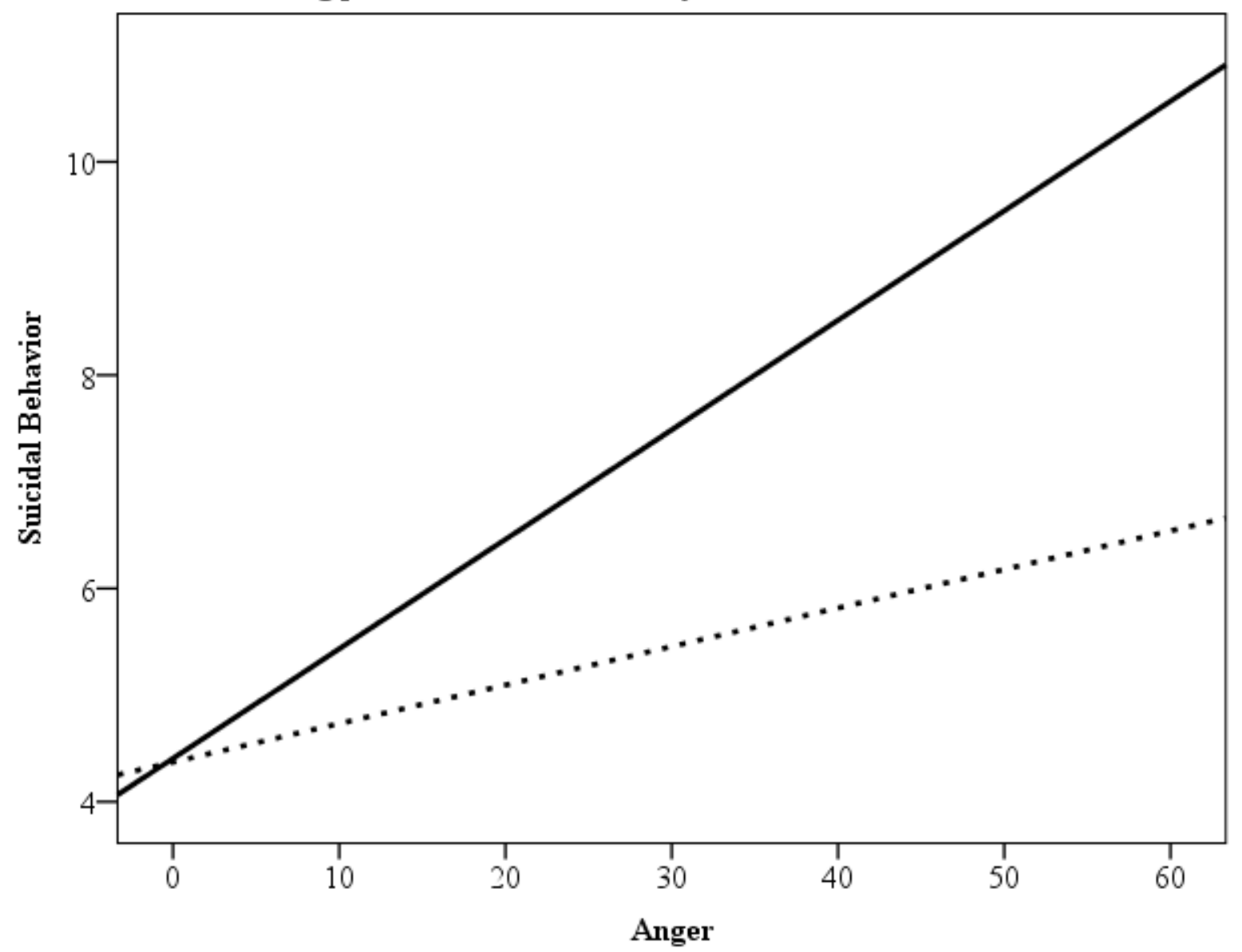

Note: Regression slopes between anger and suicidal behavior across Predominantly crime and sibling/peer victimization (dashed line with a flatter slope) and Poly-victimization (boldline with a steeper slope) classes 
Table 1

Distribution of the five types of childhood victimization experiences across males and females

\begin{tabular}{|c|c|c|c|}
\hline Childhood victimization endorsed & Total & Males & Females \\
\hline & $\begin{array}{l}\text { Frequency } \\
(\%)\end{array}$ & $\begin{array}{l}\text { Frequency } \\
(\%)\end{array}$ & $\begin{array}{l}\text { Frequency } \\
(\%)\end{array}$ \\
\hline Conventional crime & $291(84.1)$ & $135(46.4)$ & $156(53.6)$ \\
\hline Robbery, force used & $179(51.7)$ & $89(58.6)$ & $90(46.6)$ \\
\hline Stealing & $194(56.1)$ & $91(59.9)$ & $103(53.4)$ \\
\hline Vandalism & $202(58.4)$ & $92(60.5)$ & $110(57.0)$ \\
\hline Physical assault with a weapon & $135(39.0)$ & $66(43.4)$ & $69(35.8)$ \\
\hline Physical assault without weapon & $210(60.7)$ & $103(67.8)$ & $107(55.4)$ \\
\hline Attempted assault & $119(34.4)$ & $64(42.1)$ & $55(28.5)$ \\
\hline Threaten to hurt & $207(59.8)$ & $90(59.2)$ & $117(60.6)$ \\
\hline Kidnap, attempted or complete & $65(18.8)$ & $39(25.7)$ & $26(13.5)$ \\
\hline Bias attack & $67(19.4)$ & $41(27.0)$ & $26(13.5)$ \\
\hline Childhood maltreatment & $222(64.2)$ & $108(48.9)$ & $113(51.1)$ \\
\hline Physical abuse not spanking & $168(48.6)$ & $85(55.9)$ & $82(42.5)$ \\
\hline Emotional abuse & $166(48.0)$ & $71(46.7)$ & $95(49.2)$ \\
\hline Neglect & $109(31.5)$ & $48(31.6)$ & $61(31.6)$ \\
\hline Custodial inference/abduction & $80(23.1)$ & $41(27.0)$ & $39(20.2)$ \\
\hline Peer/sibling violence & $273(78.9)$ & $123(45.1)$ & $150(54.9)$ \\
\hline Assault by group of peers & $88(25.4)$ & $56(36.8)$ & $32(16.6)$ \\
\hline Peer/sibling assault & $206(59.5)$ & $94(61.8)$ & $112(58.0)$ \\
\hline Genital assault, another child & $101(29.2)$ & $69(45.4)$ & $32(16.6)$ \\
\hline Bullying & $161(46.5)$ & $72(47.4)$ & $89(46.1)$ \\
\hline
\end{tabular}




\begin{tabular}{|c|c|c|c|}
\hline Teasing/emotional bullying & $205(59.2)$ & $90(59.2)$ & $115(59.6)$ \\
\hline Dating violence & $82(23.7)$ & $44(28.9)$ & $38(19.7)$ \\
\hline Sexual violence & $219(63.3)$ & $96(43.8)$ & $123(56.2)$ \\
\hline Sexual assault, known adult & $105(30.5)$ & $49(32.2)$ & $56(29.0)$ \\
\hline Sexual assault, unknown adult & $66(19.1)$ & $39(25.7)$ & $27(14.0)$ \\
\hline Sexual assault, peer & $107(31.0)$ & $58(38.2)$ & $49(25.4)$ \\
\hline Rape, attempted or complete & $97(28.0)$ & $44(28.9)$ & $53(27.5)$ \\
\hline Sexual exposure/flashing & $113(32.9)$ & $49(32.2)$ & $64(33.2)$ \\
\hline Indirect sexual abuse, writing & $115(33.2)$ & $55(36.2)$ & $60(31.1)$ \\
\hline Sexual play, with adult & $106(30.6)$ & $47(30.9)$ & $59(30.6)$ \\
\hline Witnessed indirect violence & $237(68.5)$ & $107(45.3)$ & $129(54.7)$ \\
\hline Witness domestic violence & $103(29.8)$ & $46(30.3)$ & $57(29.5)$ \\
\hline Witness physical abuse & $102(29.5)$ & $49(32.2)$ & $52(26.9)$ \\
\hline Witness assault with a weapon & $127(36.7)$ & $69(45.4)$ & $57(29.5)$ \\
\hline Witness assault without a weapon & $170(49.1)$ & $82(53.9)$ & $87(45.1)$ \\
\hline Household theft & $136(39.3)$ & $64(42.1)$ & $72(37.3)$ \\
\hline Someone close murdered & $128(37.0)$ & $61(40.1)$ & $66(34.2)$ \\
\hline Exposure to shooting, bombs, riots & $74(21.4)$ & $42(27.6)$ & $31(16.1)$ \\
\hline Exposure to war & $43(12.4)$ & $30(19.7)$ & $12(6.2)$ \\
\hline
\end{tabular}

Note: Percentages showed in the male and female columns are calculated based on total number of specific childhood victimizations.

$* p<.05$. 
Table 2

Fit indices for the latent class models with two to five classes of childhood victimization experiences with a three-class solution being the optimal

\begin{tabular}{|c|c|c|c|c|c|}
\hline $\begin{array}{l}\text { Number of } \\
\text { classes }\end{array}$ & $\begin{array}{l}\text { LMR } \\
\text { ( } p \text { value) }\end{array}$ & Entropy & AIC & BIC & $\begin{array}{l}\text { Adjusted } \\
\text { BIC }\end{array}$ \\
\hline 2 & $\begin{array}{l}310.03 \\
(.000)\end{array}$ & .82 & $1,525.96$ & $1,568.26$ & $1,533.38$ \\
\hline 3 & $\begin{array}{l}26.21 \\
(.03)\end{array}$ & .74 & $1,511.00$ & $1,576.39$ & $1,522.46$ \\
\hline 4 & $\begin{array}{l}17.22 \\
(.06)\end{array}$ & .83 & $1,505.29$ & $1,593.76$ & $1,520.80$ \\
\hline 5 & $\begin{array}{l}10.86 \\
(.09)\end{array}$ & .86 & $1,506.12$ & $1,617.67$ & $1,525.67$ \\
\hline
\end{tabular}


Childhood victimization, anger, and suicidal behavior

Table 3

Summary of hierarchical regression analyses for class-membership, anger, and their interaction-term predicting suicidal behavior in adults

\begin{tabular}{|c|c|c|c|c|c|c|c|c|c|c|}
\hline Predictor variable & \multicolumn{5}{|c|}{ Model 1} & \multicolumn{5}{|c|}{ Model 2} \\
\hline & $\beta$ & $F$ & $R$ & $R^{2}$ & $\Delta R^{2}$ & $\beta$ & $F$ & $R$ & $R^{2}$ & $\Delta R^{2}$ \\
\hline Step 1 & & $4.36^{*}$ & .16 & .03 & .03 & & $4.36^{*}$ & .16 & .03 & .03 \\
\hline Age & $-.13 *$ & & & & & $-.13 *$ & & & & \\
\hline Gender & -.07 & & & & & -.07 & & & & \\
\hline Step 2 & & $18.74 * * *$ & .43 & .19 & .16 & & $18.23 * * *$ & .43 & .18 & .16 \\
\hline Age & -.06 & & & & & -.04 & & & & \\
\hline Gender & .003 & & & & & .00 & & & & \\
\hline Class & $-.16 * *$ & & & & & $-.15^{* *}$ & & & & \\
\hline Anger & $.36 * * *$ & & & & & $.37 * * *$ & & & & \\
\hline Step 3 & & $14.95 * * *$ & .43 & .19 & .00 & & $15.53 * * *$ & .44 & .19 & .01 \\
\hline Age & -.06 & & & & & -.03 & & & & \\
\hline Gender & .003 & & & & & -.003 & & & & \\
\hline
\end{tabular}


Childhood victimization, anger, and suicidal behavior

$\begin{array}{llc}\text { Class } & -.15 & -.004 \\ \text { Anger } & .36^{* * * *} & .42^{* * *} \\ \text { Class*Anger } & -.01 & -.18^{*}\end{array}$

Model 1 = Predictor is Class 1 vs. Class 3 (Least victimization vs. Poly-victimization). Model 2 = Predictor variable is Class 2 vs. Class 3

(Predominantly crime and sibling/peer victimization vs. Poly-victimization).

$* p<.05$

$* * p<.01$

$* * * p<.001$ 